\title{
Antitubercular therapy — an uncommon side effect
}

\author{
Mayank Kapur, Nitesh Gupta, Neeraj Kumar Gupta, Shibdas Chakrabarti, Rohit Kumar, Pranav Ish
}

Vardhman Mahavir Medical College \& Safdarjung Hospital, New Delhi, India

A 43-year-old female presented with complaints of chest pain, non-productive cough, shortness of breath, diarrhoea, loss of weight and appetite, and generalised malaise for a period of one month [3]. The chest X-ray demonstrated a massive right-sided pleural effusion. Subsequently, pleural fluid reports revealed an exudative effusion with predominantly mononuclear cells, negative malignant cytology and no growth in pyogenic culture as well as a Mycobacteria Growth Indicator Tube (MGIT) culture. Contrast-enhanced computed tomography (CECT) demonstrated a loculated pleural effusion with right middle lobe pneumonia. CECT of the abdomen revealed diffuse circumferential enhancing thickness of the terminal ilium and ileocecal junction with enlarged lymph nodes. The Mantoux test was positive $(30 \mathrm{~mm})$. The baseline haematologic and organ function tests were within normal ranges. The absence of sputum production and failure to induce sputum led to a request for bronchoscopy in order to obtain a microbiological diagnosis. Unfortunately, the patient did not provide consent to have this procedure. Thus, based on the clinic-radiological profile and the fact that the region was TB endemic, the patient was initiated on weight-based Antitubercular therapy (ATT) comprising of isoniazid (300 mg), rifampicin (600 mg), pyrazinamide (1600 mg), and ethambutol (1100 mg). However, within two days of therapy, the patient complained of general pruritus, especially over all four limbs, and exanthematous lesions in the extensor aspects. Symptomatic therapy comprising oral antihistaminic drugs and topical steroids provided partial relief. Investigations revealed a haemoglobin $(\mathrm{Hb})$ level of 12.3 gram \%, a total leucocyte count (TLC) of $9200 / \mathrm{mm}^{3}$ (comprising 36\% eosinophils), and an absolute eosinophil count (AEC) of 3312/mm. A detailed work-up as a result of eosinophilia revealed normal spirometry results (testing for asthma) and a normal stool examination (testing for helminthic infection). Liver function tests also revealed transaminitis (Aspartate transaminase - $252 \mathrm{IU} / \mathrm{L}$; Alanine transaminase - $240 \mathrm{IU} / \mathrm{L}$ ). A diagnosis of ATT-induced drug rash with eosinophilia and systemic symptoms (DRESS) was made. On discontinuing ATT, the AEC decreased to $380 / \mathrm{mm}^{3}$. The patient was also provided with symptomatic relief.

Drug rash with eosinophilia and systemic symptoms (DRESS) syndrome is a severe adverse drug reaction characterized by an extensive skin rash associated with visceral organ involvement, lymphadenopathy, eosinophilia, and atypical lymphocytosis [1]. The syndrome is characterized by a latency period ranging from 3 weeks to 3 months after the introduction of the offending drug. The range of eosinophilia may determine the involvement of internal organs with pulmonary infiltrates. In general, eosinophilia may be observed about 1 to 2 weeks after the onset of the syndrome, or can even occur after the increase in liver enzymes has normalized [2]. Multiple diagnostic criteria have been proposed for the diagnosis of DRESS syndrome by organizations including the European Registry of severe cutaneous adverse reactions (RegiSCAR), the Japanese research committee on severe acute cutaneous reactions (J-SCAR), and by Bocquet et al. [3], which require that the three criteria of cutaneous involvement, eosinophilia, and systemic involvement (lymphadenopathy, transaminitis or nephropathy) are fulfilled. The index case had cutaneous eruptions, eosinophilia, and systemic manifestations (increased liver enzymes $>2$ times greater than normal). There are only a few case reports of DRESS syndrome developing after taking ATT which all improved on cessation of therapy [4]. All ATT drugs have been implicated in causing DRESS, with isoniazid and rifampicin being most common [5]. The index case also demonstrated a reappearance of a rash and eosinophilia on attempted reintroduction of both drugs. As a result, the patient was eventually shifted to a modified therapy as per national guidelines. A large case series conducted over ten years documented only 67 cases of DRESS syndrome due to ATT with mortality in two patients [6]. Thus, DRESS is rare, but can also be life-threatening.

To conclude, a high index of suspicion and regular follow-up are the keys to an early diagnosis of DRESS syndrome in order for the offending drugs to be stopped early.

Address for correspondence: Pranav Ish, Vardhman Mahavir Medical College \& Safdarjung Hospital, New Delhi, India, e-mail: pranavish2512@gmail.com Conflict of interest: None declared

DOI: 10.5603/ARM.a2021.0097 | Received: 22.03.2021 | Copyright (C 2021 PTChP | ISSN 2451-4934 | e-ISSN 2543-6031

This article is available in open access under Creative Common Attribution-Non-Commercial-No Derivatives 4.0 International (CC BY-NC-ND 4.0) license, allowing to download articles and share them with others as long as they credit the authors and the publisher, but without permission to change them in any way or use them commercially. 

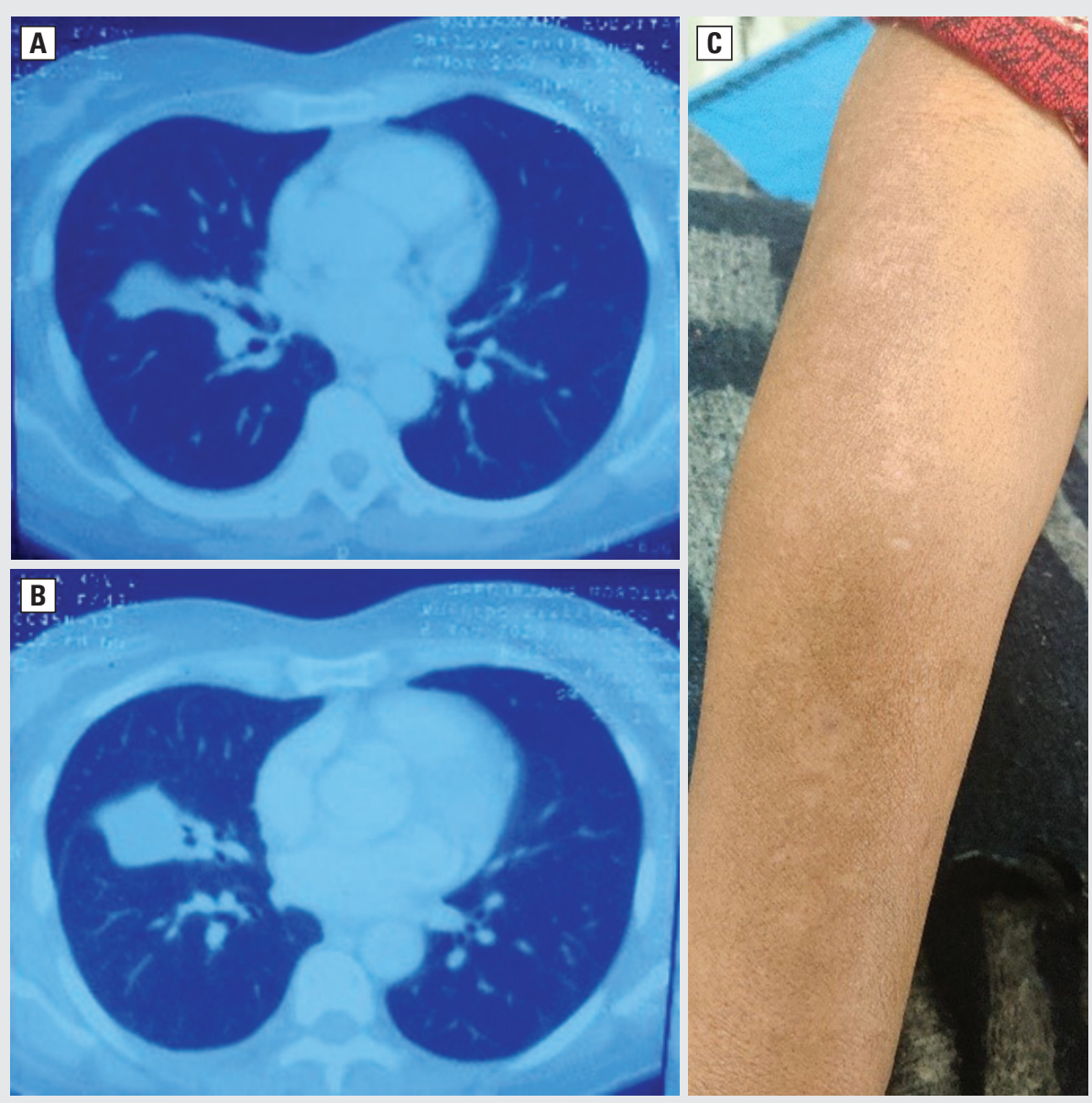

Figure 1. A, B. Computed tomography of the chest showing right middle lobe consolidation; C. Exanthematous rash over the right leg

\section{References:}

1. Kardaun SH, Sidoroff A, Valeyrie-Allanore L, et al. Variability in the clinical pattern of cutaneous side-effects of drugs with systemic symptoms: does a DRESS syndrome really exist? Br J Dermatol. 2007; 156(3): 609-611, doi: 10.1111/j.1365-2133.2006.07704.x, indexed in Pubmed: 17300272.

2. Kano Y, Ishida T, Hirahara K, et al. Visceral involvements and long-term sequelae in drug-induced hypersensitivity syndrome. Med Clin North Am. 2010; 94(4): 743-59, xi, doi: 10.1016/j.mcna.2010.03.004, indexed in Pubmed: 20609861.

3. Bocquet H, Bagot M, Roujeau JC. Drug-induced pseudolymphoma and drug hypersensitivity syndrome (Drug Rash with Eosinophilia and Systemic Symptoms: DRESS). Semin Cutan Med Surg. 1996; 15(4): 250-257, doi: 10.1016/s1085-5629(96)80038-1, indexed in Pubmed: 9069593.

4. Jridi S, Azzeddine R, Bourkadi JE. [DRESS syndrome secondary to antituberculosis drugs: about a case]. Pan Afr Med J. 2017; 27: 37, doi: 10.11604/pamj.2017.27.37.11663, indexed in Pubmed: 28761613.

5. Coster A, Aerts O, Herman A, et al. Drug reaction with eosinophilia and systemic symptoms (DRESS) syndrome caused by firstline antituberculosis drugs: Two case reports and a review of the literature. Contact Dermatitis. 2019; 81(5): 325-331, doi: 10.1111/ cod.13296, indexed in Pubmed: 31021423.

6. Allouchery M, Logerot S, Cottin J, et al. French Pharmacovigilance Centers Network and the French Investigators for skin adverse reactions to drugs. Antituberculosis drug-associated DRESS: a case series. J Allergy Clin Immunol Pract. 2018; 6(4): 1373-1380, doi: 10.1016/j.jaip.2017.11.021, indexed in Pubmed: 29274824. 